Journal of Computer Science 4 (1): 51-58, 2008

ISSN 1549-3636

(C) 2008 Science Publications

\title{
Computation of a Single-phase Shell-Type Transformer Windings Forces Caused by Inrush and Short-circuit Currents
}

\author{
${ }^{1}$ M.B.B. Sharifian, ${ }^{2}$ R. Esmaeilzadeh, ${ }^{1}$ M. Farrokhifar, ${ }^{3}$ J. Faiz, \\ ${ }^{1}$ M. Ghadimi and ${ }^{1}$ G. Ahrabian \\ ${ }^{1}$ Faculty of Electrical and Computer Engineering, University of Tabriz, Tabriz, Iran \\ ${ }^{2}$ Azarbaijan Regional Electric Company, Tabriz, Iran \\ ${ }^{3}$ Department of Electrical and Computer Engineering, University of Tehran, Tehran, Iran
}

\begin{abstract}
This research studies the forces on the windings of transformer due to inrush current. These forces are compared with the corresponding forces due to short-circuit of the windings. Twodimensional finite element computation of a single-phase shell-type transformer is carried out based on the maximum permissible inrush current value where its amplitude is the same as the rated shortcircuit current. To verify the computation results, they are compared with those recently obtained using Artificial Neural Network (ANN).
\end{abstract}

Key words: Inrush current, transformer, short circuit, finite element method

\section{INTRODUCTION}

One of major reason for fault in power transformers is deterioration of winding and insulation of conductors due to the oscillations resulted from the electrodynamics forces. The over-current and rated current result in the above-mentioned forces. Therefore, the transformers coils must be protected mechanically and connected to each other by ribbon and wedges. The structural criterion for this support is generally those forces that are generated by the maximum possible current $^{[1]}$.

A large transient current during a short-circuit apply abnormal electromechanical forces upon the windings of transformer that may damage the whole windings. Short-circuit forces and resultant stresses must be predicted in the design stage. These forces must be in the range that is specified by manufacturer. Inrush currents pass through transformer repeatedly during its switching process and it may lead to very large amplitude and large electromechanical forces. Difference between the inrush current and short circuit current is that the inrush current may last several $10 \mathrm{sec}$, while the fault current diminishes shorter than $10 \mathrm{~ms}^{[2]} . \mathrm{In}^{[2]}$, the core has been taken to be infinitely permeable. The local magnetic energy outside the core has been represented in terms of a quadratic function of the vector magnetization potential. A solution for the unknown vector potential value has been obtained using a Hopfield neural network as described in $^{[3]}$. The obtained field distribution has been used to compute forces $^{[2]}$. In addition, repetition of the inrush current is much larger than the short circuit current. Out-of-phase synchronizing (disadvantage of parallel transformer with the power system) may also lead to unbalanced mmf in the step-up transformer. Forces calculation shows that in such case the axial forces in the windings can be 2-10 times of the corresponding forces in the short circuit case ${ }^{[4]}$.

The main objects of this study are two-dimensional computation of the forces on the coils of a single-phase shell-type transformer. The results are then compared with those obtained with a short-circuited winding. Before such calculation, inrush current is analyzed and the fundamental equations are derived. The computation results are compared with those obtained by application of $\mathrm{ANN}^{[2]}$.

\section{TRANSIENT CURRENT FOR TRANSFORMER CONNECTED TO POWER LINE}

After a transformer is connected to the power line, flux and current pass a transient mode and then reaches the steady-state mode. Voltage waveform, instant of closing the switch, amplitude and direction of the magnetic residual are the factors that can last the transient mode. The primary current with secondary open-circuit may rise to several times the rated current of the transformer. This phenomenon has the following dangerous effects:

Corresponding Author: M.B.B. Sharifian, Faculty of Electrical and Computer Engineering, University of Tabriz, Tabriz, Iran 
- Generating very large mechanical forces between the windings and its components

- Unequal voltage distribution over different parts of the windings and turns

- Over current in the windings

The above-mentioned effects are more important in high power transformers. The major quantities in the transient mode are over currents and sudden voltages due to connecting transformer to the power line or short-circuit fault.

\section{INRUSH CURRENT IN A SINGLE-PHASE TRANSFORMER}

Suppose that the voltage:

$$
\mathrm{v}_{1}=\mathrm{V}_{1 \mathrm{~m}} \sin \left(\omega \mathrm{t}-\varphi_{0}\right)
$$

is applied at the moment the transformer first connected to the power line, where the phase difference $\varphi_{0}$ determines voltage $\mathrm{v}_{1}$ at the instant of connecting the transformer to the power line $(\omega t=0)$. As Fig. 1 shows at $\omega \mathrm{t}=0, \mathrm{v}_{1}=\mathrm{ab}$, the steady-state flux corresponding to this voltage is $\varphi_{p}=$ ac. Neglecting the residual effect, $i_{0}$ and $\varphi_{0}$ at instant of connecting are zero. In the transformer, flux called the free flux $\varphi_{1}$, opposite to the steady-state flux, $\varphi_{\mathrm{p}}$, appears:

$$
\varphi_{\mathrm{p}}+\varphi_{1}=0
$$

If the winding resistance is neglected, the electromagnetic energy due to $\varphi_{1}$ cannot diminish automatically. Consequently, the amplitude and sign of this flux remains constant over undefined period (dotted lines in Fig. 1). Sum of $\varphi_{p}$ and sinusoidal $\varphi_{1}$ may saturate the core more rapidly and core magnetization current $\mathrm{i}_{\mathrm{m}}$ increases proportionally.

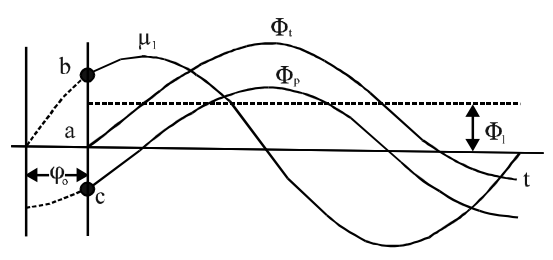

Fig.1. Primary voltage and flux waveforms

Actually $r_{1}$ is not zero, the electromagnetic energy due to $\varphi_{1}$ is diminished in $r_{1}$ and tends to zero gradually. Eq. 1 is now rewritten as follows:

$$
\mathrm{v}_{1}=\mathrm{ri}_{0}+\mathrm{N}_{1} \frac{\mathrm{d} \varphi_{\mathrm{t}}}{\mathrm{dt}}
$$

where, $\varphi_{t}=f\left(i_{0}\right)$ depends on the nature of the core magnetization and is difficult to determine it. Assuming a linear magnetic circuit, then:

$$
\varphi_{\mathrm{t}} \mathrm{N}_{1}=\mathrm{L}_{1} \mathrm{i}_{0}
$$

Substituting $\mathrm{i}_{0}$ from (4) into (1):

$$
\begin{aligned}
& \mathrm{V}_{1 \mathrm{~m}} \sin \left(\omega \mathrm{t}+\varphi_{0}\right)=\frac{\varphi_{\mathrm{t}} \mathrm{N}_{1}}{\mathrm{~L}_{1}} \mathrm{r}_{1}+\mathrm{N}_{1} \frac{\mathrm{d} \varphi_{\mathrm{t}}}{\mathrm{dt}} \\
& \text { or } \\
& \frac{\varphi_{\mathrm{t}}}{\mathrm{L}_{1}} \mathrm{r}_{1}+\frac{\mathrm{d} \varphi_{\mathrm{t}}}{\mathrm{dt}}=\frac{\mathrm{V}_{1 \mathrm{~m}}}{\mathrm{~N}_{1}} \sin \left(\omega \mathrm{t}+\varphi_{0}\right)
\end{aligned}
$$

The right-hand side of differential Eq. 5 is a sinusoidal function and its solution consists of an exponential transient function $\varphi_{1}$ and the steady-state sinusoidal function $\varphi_{\mathrm{p}}$ :

$$
\varphi_{\mathrm{t}}=\varphi_{\mathrm{p}}+\varphi_{1}
$$

On the other hand, for a no-load transformer $\varphi_{\mathrm{p}}$ lags $90^{\circ}$, thus:

$$
\varphi_{\mathrm{p}}=\varphi_{\mathrm{m}} \sin \left(\omega \mathrm{t}+\varphi_{0}-\frac{\pi}{2}\right)=-\varphi_{\mathrm{m}} \cos \left(\omega \mathrm{t}+\varphi_{0}\right)
$$

And the transient component of the flux is:

$$
\varphi_{1}=\mathrm{Ce}^{\frac{-\mathrm{r}_{1} \mathrm{t}}{\mathrm{L}_{1}}}
$$

At $t=0$, there is residual flux $\pm \varphi_{\text {rem }}$, thus:

$$
\begin{aligned}
& \varphi_{1}=\varphi_{\mathrm{p}}+\varphi_{1}= \pm \varphi_{\mathrm{rem}}=-\varphi_{\mathrm{m}} \cos \varphi_{0}+\mathrm{C} \\
& \Rightarrow \mathrm{C}=\varphi_{\mathrm{m}} \cos \varphi_{0} \pm \varphi_{\mathrm{rem}}
\end{aligned}
$$

Thus:

$$
\varphi_{\mathrm{t}}= \pm \varphi_{\mathrm{m}} \cos \varphi_{0} \mathrm{e}^{\frac{-\mathrm{r}_{\mathrm{t}} \mathrm{t}}{\mathrm{L}_{1}}} \pm \varphi_{\mathrm{rem}} \mathrm{e}^{\frac{-\mathrm{r}_{1} \mathrm{t}}{\mathrm{L}_{1}}}
$$

Thus, $\varphi_{\mathrm{t}}$ will be as follows:

$$
\varphi_{1}=\varphi_{\mathrm{m}} \cos \left(\omega \mathrm{t}+\varphi_{0}\right)+\varphi_{\mathrm{m}} \cos \varphi_{0} \mathrm{e}^{\frac{-\mathrm{r}_{\mathrm{r}} \mathrm{t}}{\mathrm{L}_{1}}} \pm \varphi_{\mathrm{rem}} \mathrm{e}^{\frac{-\mathrm{r}_{\mathrm{L}} \mathrm{t}}{\mathrm{L}_{1}}}
$$


As shown in Eq. 9, to achieve the most required case at the time of connection to the power line, $\varphi_{0}$ must be equal to $90^{\circ}$ and $\varphi_{\text {rem }}=0$, thus:

$$
\varphi_{\mathrm{p}}=-\varphi_{\mathrm{m}} \cos \left(\omega \mathrm{t}+\frac{\pi}{2}\right)=\varphi_{\mathrm{m}} \sin \omega \mathrm{t}
$$

In this case, just after connecting the transformer to the power line the transformer flux will approach the steady-state and there is no transient period. The worse case for $\varphi_{0}=0$ at instant $\mathrm{t}=0$ is $\mathrm{v}_{1}=0$ and also the sign of $\varphi_{1}$ is opposite to the sign of $\varphi_{\mathrm{p}}$.

Amplitude of the no-load current at instant of connecting the transformer to the power line may be several times of the corresponding current amplitude $\left(\mathrm{I}_{\mathrm{om}}\right)$ of steady-state of the transformer. The test shows that for $\mathrm{B}=1.4 \mathrm{~T}$, the ratio $\mathrm{I}_{\mathrm{omax}} / \mathrm{I}_{\mathrm{om}}$ is between 50 and 80 and for larger $\mathrm{B}$ it tends to $120^{[5]}$. Considering $I_{o} \approx 5 \% I_{r}$, the no load current after the transformer is connected to the line may reach to 4 to 6 times the rated current. Because $r_{1} \prec \prec \omega L_{1}$, the transient current $I_{0}$ is slowly diminished, for example after passing $1 \mathrm{sec}$ of the connection, its value becomes three times the normal case. In the high power and high voltage transformers, this time tends to $20 \mathrm{sec}$ and more ${ }^{[6]}$.

The transient current of connection of the transformer is not dangerous but it may disconnect the transformer from the power line ${ }^{[7]}$ and therefore a proper protection is required.

\section{SUDDEN SHORT-CIRCUIT CURRENTS}

Short-circuit current can be obtained from the short-circuit equivalent of transformer as follows:

$$
i_{s c}=-I_{s c} \sqrt{2} \cos (\omega t+\alpha)+I_{s c} \sqrt{2} \cos \alpha e^{\frac{-\mathrm{r}_{\mathrm{sc}}}{\mathrm{L}_{\mathrm{sc}}}}
$$

The worst case appears when $\alpha$ is equal to zero:

$$
i_{s c} I_{(\alpha=0)}=-I_{s c} \sqrt{2} \cos \omega t+I_{s c} \sqrt{2} e^{\frac{-r_{s c}}{L_{s c}}}
$$

If the short-circuit occurs when the rated line voltage applied, then:

$$
\mathrm{I}_{\mathrm{sc}} \sqrt{2}=\frac{100 \sqrt{2}}{\mathrm{~V}_{\mathrm{sc}}} \mathrm{I}_{\mathrm{n}}
$$

Assuming $r_{s c} / L_{s c}=0, i_{s c}$ does not diminish. For the larger ratio, $i_{\mathrm{sc}}$ diminishes quicker. After passing a half period of sudden short circuit, amplitude of $i_{s c}$ tends to twice the steady-state short circuit current. Although the short-circuit duration is not so long, the temperature rise of the winding may damage the insulation. Basically, the attempt is that the temperature rise does not exceed $200^{\circ} \mathrm{C}^{[8]}$. The time of reaching the winding temperature to $250^{\circ} \mathrm{C}$ may be obtained as follows ${ }^{[9]}$ :

$$
\mathrm{t} \approx 2.5\left(\frac{\mathrm{U}_{\mathrm{sc}}}{\mathrm{J}_{\mathrm{av}}}\right)^{2}
$$

Basically, the above-mentioned time must not exceed $20 \mathrm{sec}^{10]}$.

\section{ELECTROMECHANICAL FORCES COMPUTATION IN TRANSFORMER-BACKGROUND}

Applied forces to the winding of transformer are divided into two internal and external forces. Interaction of two windings leakage fluxes and current develops internal forces and interaction of axialcomponent of the leakage flux and current generates external forces.

Finite Element (FE) techniques have been applied in order to solve the transformer problems over shorter time ${ }^{[11-14]}$. The modified T- $\Omega$ technique has been used to calculate $3 \mathrm{D}$ transient eddy current and also the applied electromechanical forces to the winding ${ }^{[15]}$. In this technique, conductibility $\sigma$ is assumed constant and the magnetic conducting materials are taken to be linear. The major advantage of the technique is considerable reduction of the unknown variables. The axial forces in a $500 \mathrm{kV}, 360$ MVA transformer have been calculated. A complex FE method has been used to simulate the fields and forces in electromagnetic devices and face-edge FE method has been applied to a magneto-static cylindrical piece. This analysis has been applied to the transformer leakage field emphasizing the forces applied to the winding due to the short-circuit current $^{[16]}$. A method has been used in a $125 \mathrm{kVA}$ aircooled single-phase model of three-phase transformer. $\operatorname{In}^{[17]}$, 2D leakage magnetic fields and short-circuits current forces in a 17 MVA transformer have been computed using FE method. The short-circuit forces consists of dc, fundamental and twice-frequency components. In the above computations, Ampere turns of the primary and secondary windings are assumed equal, but with opposite signs; saturation and eddy currents within the windings have been neglected. $\operatorname{In}^{[2]}$, Hopefield Neural Network energy minimization 
method has been used for calculation of the forces due to the inrush current. The unknown vector potential has been obtained using the mentioned network ${ }^{[18]}$. Analysis has been carried out for a $10 \mathrm{MVA}, 66 / 11 \mathrm{kV}$ transformer.

\section{ANSYS APPLICATION FOR FORCE COMPUTATION}

Maxwell stress tensor is used for force computation by Ansys FE software. This tensor is obtained from Maxwell equations. The force is equal to the surface integral of the Maxwell stress tensor as follows:

$$
\{F\}=\int\left\{\left[T_{e}\right]+\left[T_{m}\right]\right\}\{d s\}
$$

where, $\left[\mathrm{T}_{\mathrm{e}}\right]$ is the electrical Maxwell stress tensor and $\left[\mathrm{T}_{\mathrm{m}}\right]$ is the magnetic Maxwell stress tensor ${ }^{[19]}$. Magnetic analysis is carried out by creating the physical environment, meshing the model, determining the physical properties of each region, applying the boundary conditions, solving the problem and deriving the results.

\section{TWO-DIMENSIONAL FE MODEL OF A SINGLE-PHASE TRANSFORMER}

A single-phase power transformer with specifications given in Table 1 is used for the analysis.

Calculations are concentrated on worse case corresponding to the peak current. Both primary shortcircuit and inrush Ampere-turns were assumed equal to 20 times the normal value. The secondary Ampereturns, however, was assumed equal and opposite to the primary Ampere-turns; it is assumed equal to zero for inrush current case.

Table 1: Specifications of the proposed transformer

\begin{tabular}{ll}
\hline No. of turns of primary winding & 1200 \\
No. of turns of secondary winding & 200 \\
Primary rated voltage $(\mathrm{kV})$ & 66 \\
Secondary rated voltage $(\mathrm{kV})$ & 11 \\
Rated power $(\mathrm{MVA})$ & 10 \\
LV winding cross-section $(\mathrm{m} \times \mathrm{m})$ & $0.167 \times 1$ \\
HV winding cross-section $(\mathrm{m} \times \mathrm{m})$ & $0.167 \times 1$ \\
Yoke and legs dimensions $(\mathrm{m} \times \mathrm{m})$ & $0.25 \times 0.25$ \\
Window area $(\mathrm{m} \times \mathrm{m})$ & $1 \times 1$ \\
Core outer dimensions $(\mathrm{m} \times \mathrm{m})$ & $2 \times 1.5$ \\
Middle core limb & $0.5 \times 0.5 \mathrm{~m}$ \\
Outer core limb & $0.5 \times 0.25 \mathrm{~m}$ \\
Inner window radius & $0.25 \mathrm{~m}$ \\
Outer window radius & $1.25 \mathrm{~m}$ \\
Outer limb radius & $1.5 \mathrm{~m}$ \\
\hline
\end{tabular}

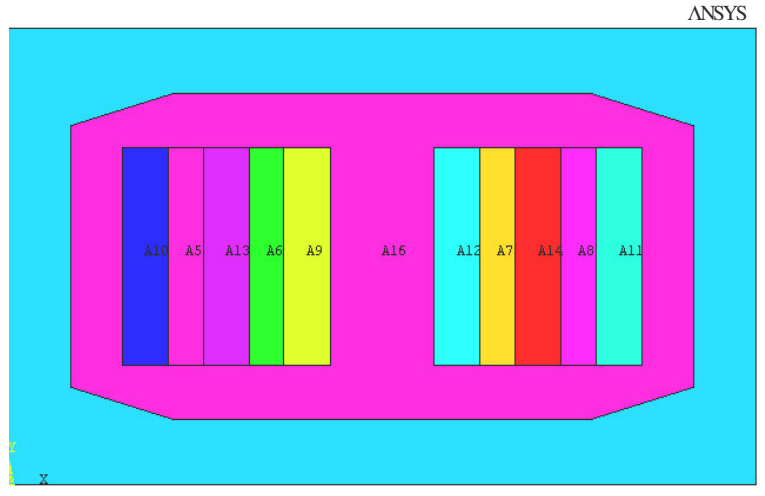

Fig. 2: Finite element model of a single-phase shelltype transformer

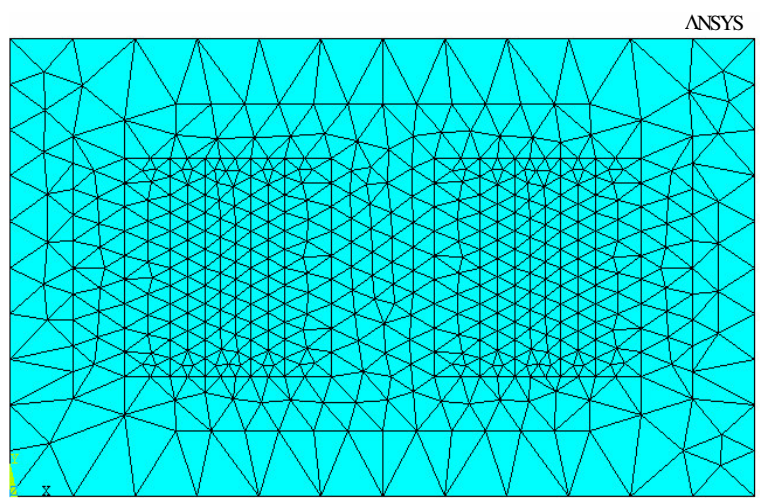

Fig. 3: Finite element meshing of the single-phase transformer

Figure 2 shows the finite element model of the single-phase shell-type transformer. Figure 3 shows its mesh modeling. Figure 4 shows the core magnetization characteristic of the transformer core laminations. The proposed mesh has 1024 elements and 2253 nodes. A polygonal with 8 nodes or triangle with 6 nodes is used. Free order for the element in each node is 4 , which are the magnetic vector potential, electric potential time integral, current and emf drop. Here, boundary parallel flux conditions have been used.

Since calculation of the maximum forces due to the inrush current and short-circuit current are proposed and field $\mathrm{B}$ at frequency equal to $50 \mathrm{~Hz}$ is in phase with the excitation emf, therefore, static analysis of the problem is suffice. The convergent of the non-linear solution of the problem is due to the short-circuit case. Figure 5 shows the flux distribution within the transformer under short-circuit current.

Figure 6 and 7 show the force distribution on the coils of the single-phase transformer when the coils are short-circuited. Figure 8-11 show the axial and radial 


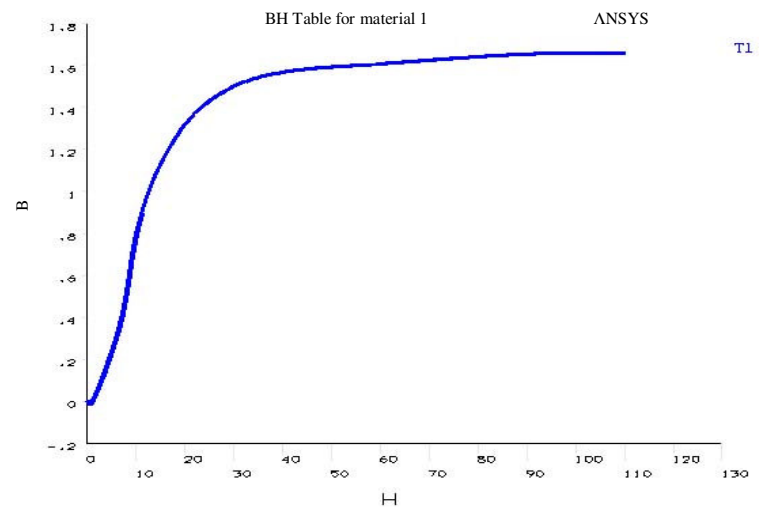

Fig. 4: Magnetization characteristics of the transformer core
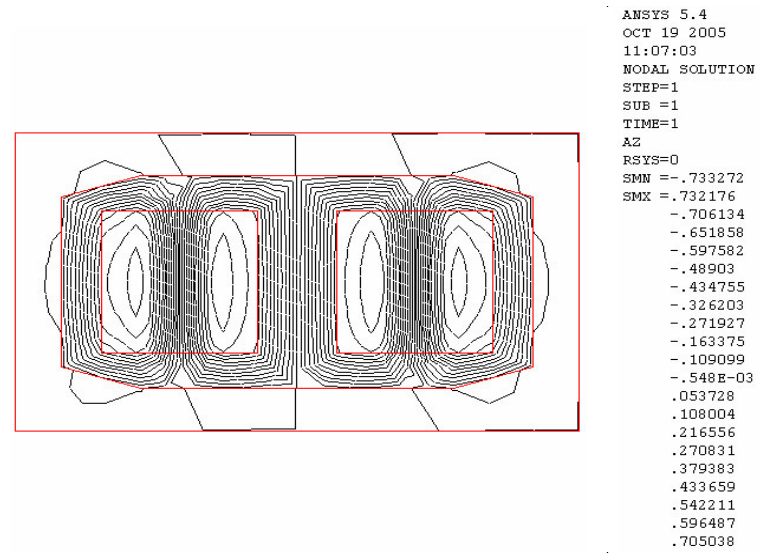

Fig. 5: Flux distribution in the short-circuited singlephase transformer
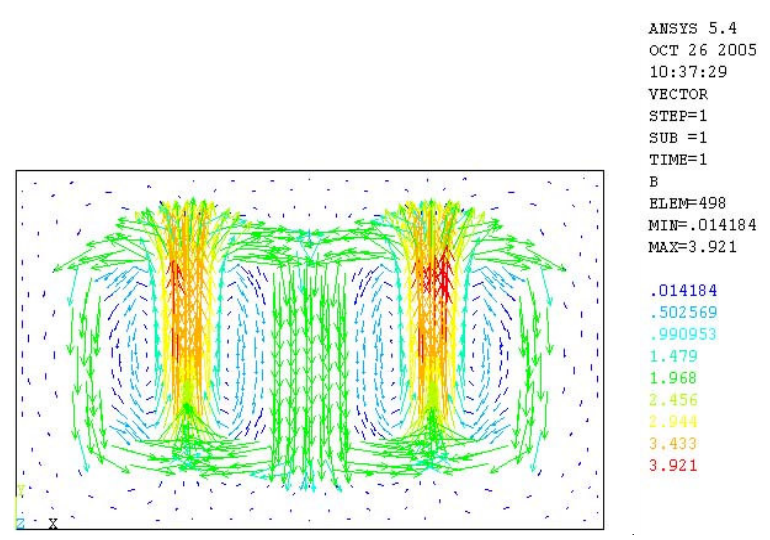

Fig. 6: Flux density distribution of the short-circuited single-phase transformer

forces versus the height of the winding in the similar case. These results indicate that the radial forces have the maximum value close to the middle of the winding

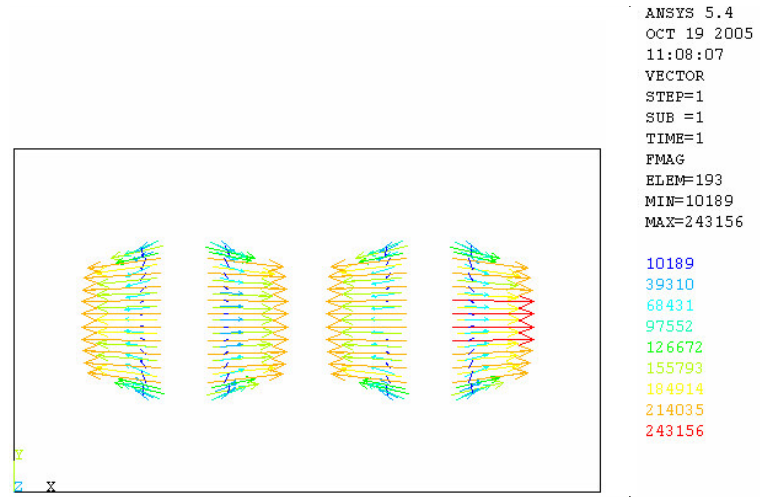

Fig. 7: Vector forces distribution on the coils of the short-circuited transformer

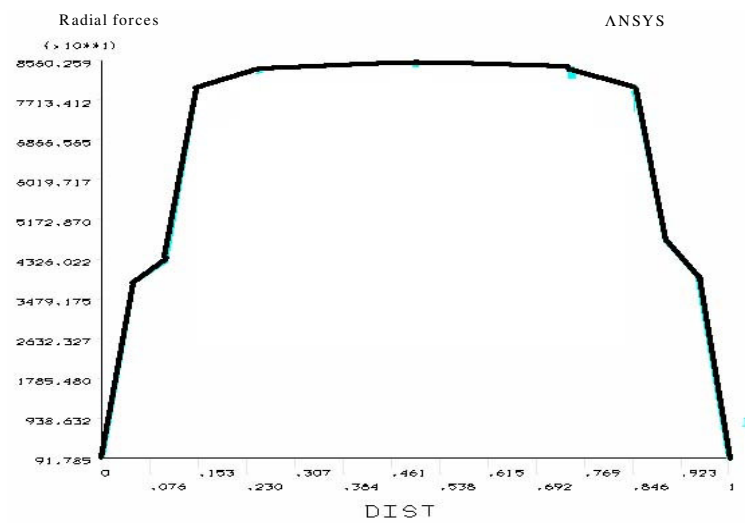

Fig. 8: Radial forces on the LV winding of the shortcircuited single-phase transformer

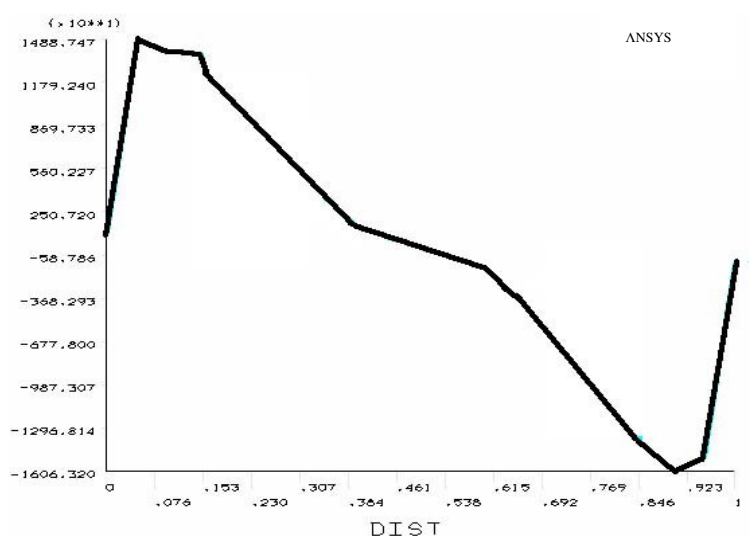

Fig. 9: Axial forces on the LV winding of the shortcircuited single-phase transformer

height. These forces tend to push the windings to the outer part. Also, the axial forces in the upper and lower parts have the peak values. These forces act in such 


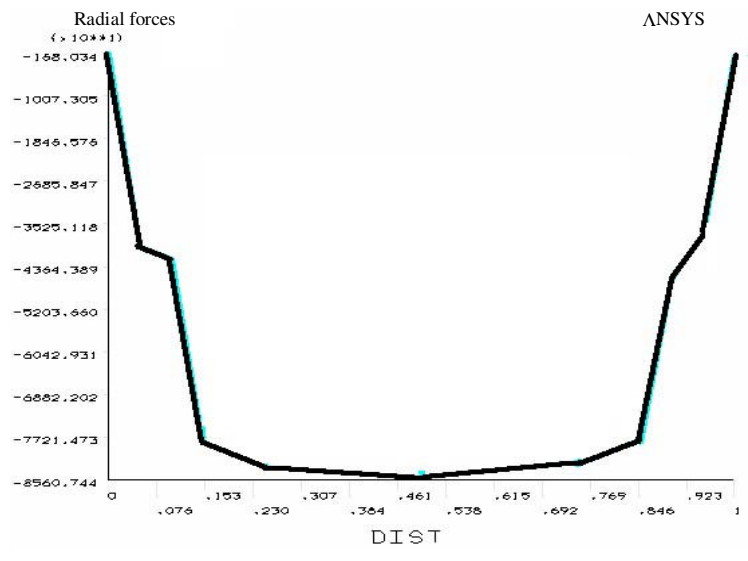

Fig. 10: Radial forces on the HV winding of the shortcircuited single-phase transformer

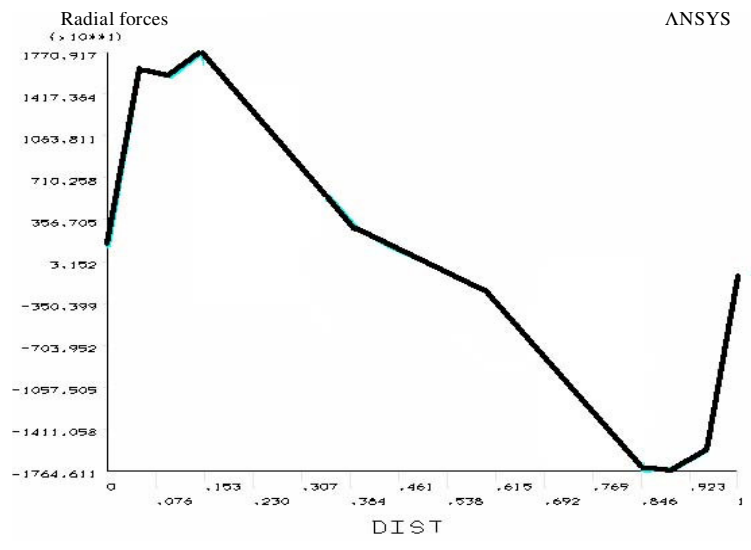

Fig. 11: Axial forces on the HV winding of the shortcircuited single-phase transformer

direction that reduces the height of the winding. In such conditions, the radial forces applied on the winding are about 4.5 times the axial forces.

Figure 12 shows the flux distribution in the singlephase transformer due to the inrush current. Figure 13 presents the vector form of the flux density distribution and Fig. 14 shows the force distribution on the winding due to the inrush currents. Figure 15 and 16 show the radial and axial forces curves versus the winding height for the LV winding, respectively. To validate the results they have been compared with those given in ${ }^{[2]}$.

For a better comparison of the axial and radial forces applied to the LV winding of the single-phase transformer in both short-circuit and inrush current cases, the result have been plotted in Fig. 17. The radial forces due to the inrush current as large as the radial forces in the short-circuit case. Also the axial forces due to the inrush current are about 3.5 times the corresponding forces in the short circuit case.

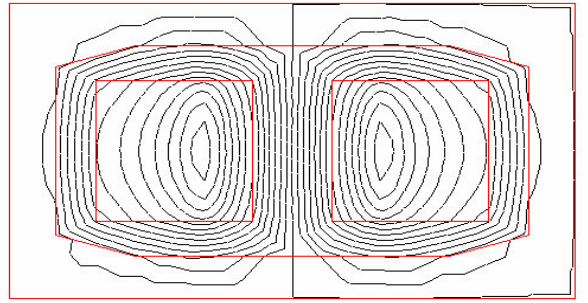

Fig. 12: Flux distribution in single-phase transformer due to inrush current

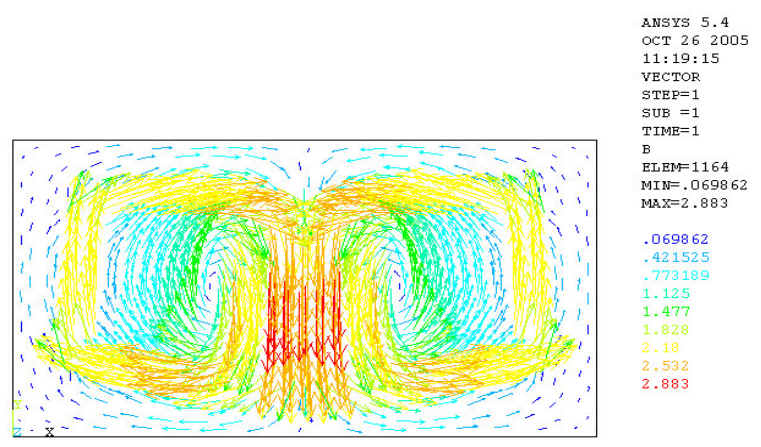

Fig. 13: Flux distribution in single-phase transformer due to inrush current

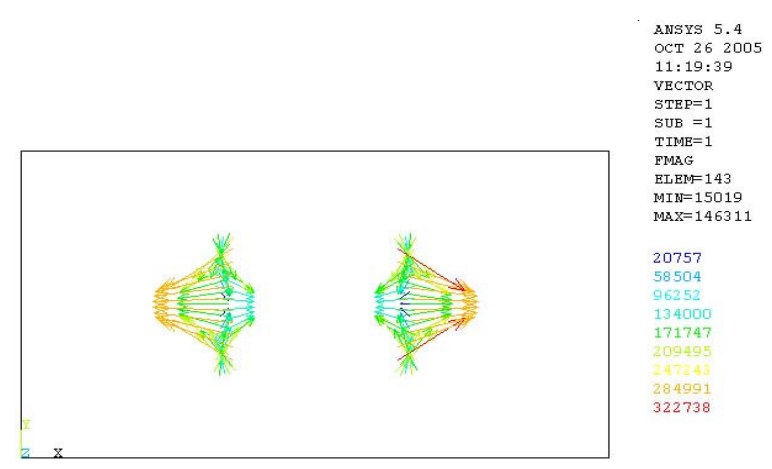

Fig. 14: Vector forces distribution $\mathrm{n}$ the winding of single-phase transformer due to inrush current

When the transformer is connected to the power line, the inrush currents generate the forces which are as large as forces due to the short-circuit and it may damage the windings. The reason is that the electromechanical stresses are applied more frequently and for longer period. These damages are largely in the form of 


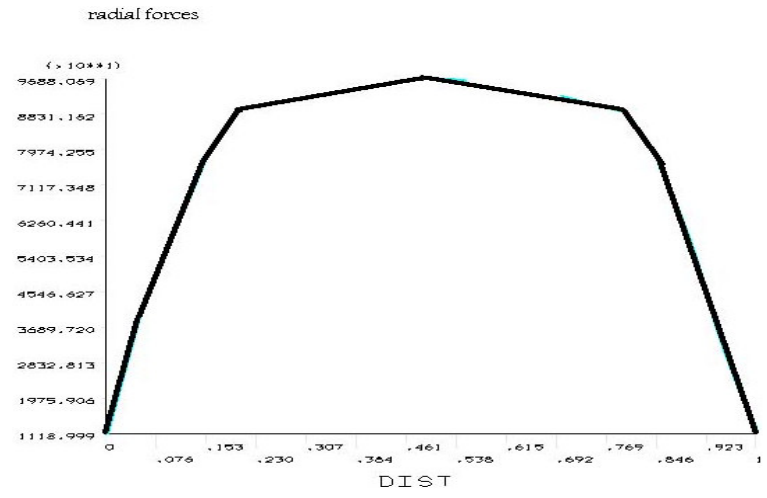

Fig. 15: Radial forces on the LV winding of singlephase transformer due to inrush current

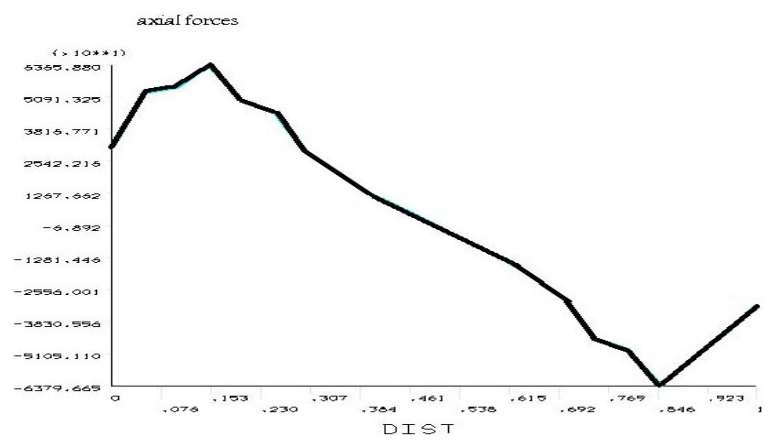

Fig. 16: Axial forces on the LV winding of singlephase transformer due to inrush current

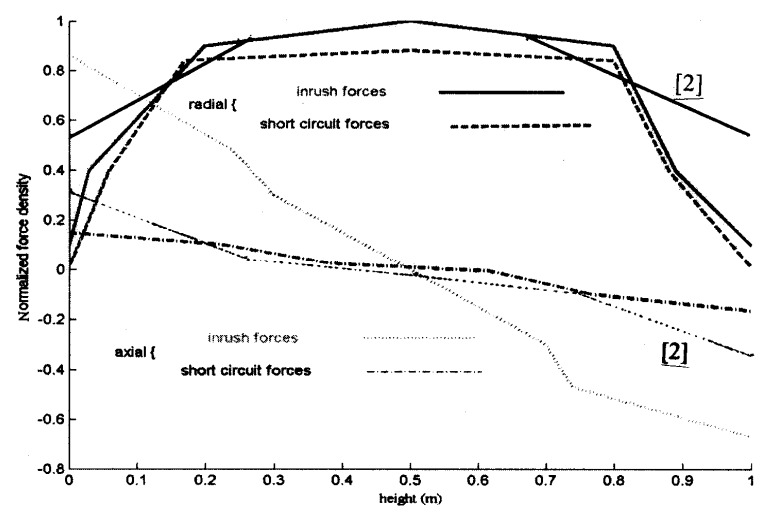

Fig. 17: Comparison of the radial and axial forces on the LV winding of the single-phase transformer in the short-circuit and inrush current cases

decreasing the insulation strength (wearing the windings and conductors in the insulation materials) and sometimes they may damage the insulation for large inrush current.

\section{CONCLUSIONS}

Two-dimensional finite element analysis of a single-phase shell-type transformer has been carried. Electromechanical forces in the windings, with maximum value of the inrush current similar to the rated short-circuit current, have been determined. The results computed using the Artificial Neural in ${ }^{[2]}$ has been compared with those obtained using FE method. $\mathrm{In}^{[2]}$, the core has been taken to be infinitely permeable, but here the actual magnetization characteristic of the core has been used and the more accurate result has been obtained compared to ${ }^{[2]}$. The results of the analysis are as follows:

- Both short circuit and inrush current can produce considerable forces on the winding of transformer

- Connecting transformer to the power line produces forces, which are as large as the force due to the short-circuit current and so they may damage the windings. The reason is the more frequent electromechanical stresses and longer time, due to the inrush current

- The axial forces due to inrush currents are larger that those produced by the short circuit current

- Force calculation under imbalanced excitation conditions such as inrush current leads to incorrect results if simplification in field computation is made in high saturation cases

- This analysis and the results can be used in the transformer design stage

\section{LIST OF SYMBOLS}

$\mathrm{N}_{1} \quad=$ No. of turns of primary winding

$\varphi_{\mathrm{t}} \quad=$ Flux due to connecting transformer to line

$\varphi_{\mathrm{av}} \quad=$ Maximum flux amplitude in steadystate

$\mathrm{r}_{\mathrm{sc}}=\mathrm{r}_{1}+\mathrm{r}_{2}^{\prime} \quad=$ Short-circuit equivalent resistance

$\mathrm{x}_{\mathrm{sc}}=\mathrm{x}_{1}+\mathrm{x}_{2}^{\prime}=$ Short-circuit equivalent reactance

$\mathrm{L}_{\mathrm{sc}}=\mathrm{L}_{1}+\mathrm{L}_{2}^{\prime}=$ Short-circuit equivalent inductance

$\mathrm{L}_{1} \quad=$ Primary winding inductance

$\mathrm{L}_{2}^{\prime} \quad=$ Secondary winding inductance referred to primary

$\mathrm{U}_{1} \quad=$ Primary voltage when secondary shortcircuited

$\mathrm{U}_{1 \mathrm{~m}} \quad=$ Maximum primary voltage when secondary short-circuited 


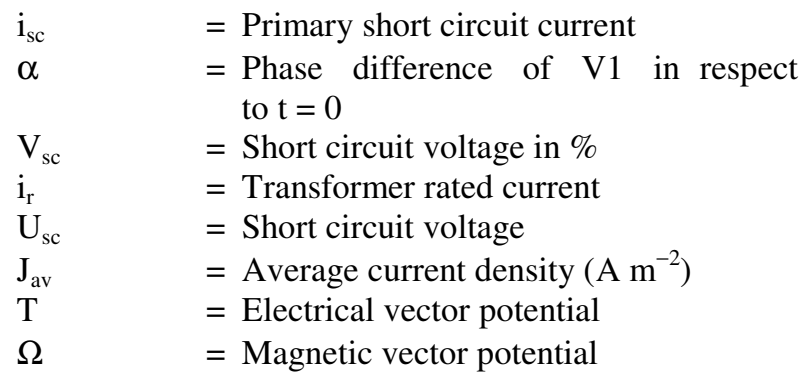

\section{REFERENCES}

1. Brunke, J.H. and K.J. Frohlich, 2001. Elimination of transformer inrush currents by controlled switching, I. Theoretical considerations. IEEE Trans. Power Delivery, 16 (2): 276-280.

2. Adly, A.A., 2001. Computation of inrush current forces on transformer windings. IEEE Trans. Magn., 37 (4): 2855-2857.

3. Yun-Qiu, T., Q. Jing-Qiu and X. Zi Hong, 1990. Numerical calculation of short-circuit electromagnetic forces on transformer winding. IEEE Trans. Magn., 26: 1039-1041.

4. Arturi, C.M., 1992. Force calculation in transformer windings under unbalanced $\mathrm{mmfs}$ by a nonlinear finite-element code. IEEE Trans. Magn., 28 (2): 1363-1366.

5. Bimbhra, P.S., 1995. Generalized Theory of Electrical Machines. 5th Edn. Khanna Publishers, Delhi.

6. Li Donoxia, Wang Zanjin and Liu Xiucheng, 2001. Modeling and simulation of magnetizing inrush current of large power transformers. International Conference on Electrical Machines and Systems, Japan (Tokyo), 1: 18-20.

7. Lin, C.E., C.L. Cheng, C.L. Huang and J.C. Yeh, 1993. Investigation of magnetizing inrush current in transformers. I. Numerical simulation. IEEE Trans. Power Delivery, 8 (1): 246-254.

8. Mittle, V.N., 1983. Design of Electrical Machines (D.C. and A.C.). 3rd Edn. Standard Publishers Distributors, Delhi.
9. William M. Flanagan, 1986. Handbook of Transformer Design and Applications. 2nd Edn. McGraw-Hill Book Company, New York.

10. Say, M.G., 1989. Alternating Current Machines. 5th Edn. John Wiley and Sons, New York.

11. Darley, V., 2000. The use of finite element techniques in the design and analysis of power transformers. IEE Seminar on use of Finite Elements (FE) in Electromechanical Design and Analysis, 147 (5): 11/1-11/4.

12. Preston, T.W. and A.B.J. Reece, 1997. Finite Element Method in Electrical Power Engineering. Oxford University Press, Oxford.

13. Darley, V., 1991. The practical application of FEM techniques in transformer design and development. ISEF Conference, Southampton, 4: 199-208.

14. Michel, Jean-Louis and Darley, Vince, 1999. Advanced numerical tools for transformers. International Conference of Power Transformer, USA, 2: 347-451.

15. Renyuan, T., L. Yan, L. Dake and T. Lijian, 1992. Numerical calculation of 3D eddy current field and short circuit electromagnetic force in large transformers. IEEE Trans. Magn., 28 (2): 1418-21.

16. Di Barba, P., A. Savini and I. Perugia, 1998. Mixed finite elements for the simulation of fields and forces in electromagnetic devices. IEEE Trans. Magn., 34 (5): 3572-3575.

17. Yun-Qiu, T., Q. Jing-Qiu and X. Zi-Hong, 1990. Numerical calculation of short circuit electromagnetic forces on the transformer winding. IEEE Trans. Magn., 26 (2): 1039-1041.

18. Adly, A.A. and S.K. Abd-El-Hafiz, 2000. Utilizing Hopfield neural networks in the analysis of reluctance motors. IEEE Trans. Magn., 36 (5): 3147-3149.

19. ANSYS_Ver. 5.4 Finite Element Software, Manual and Documentation, Theory Manual, 1997. 